\title{
El "Cemical": un medio de solución de conflictos para la función pública local
}

Joan Mauri Majós *

\section{Los medios de solución de conflictos en la relación de empleo público}

En el sistema de relaciones laborales el conflicto que afecta a los intereses colectivos de los trabajadores se canaliza a través de la negociación colectiva entre las partes.

Dicha negociación puede perseguir la determinación de las condiciones de trabajo a través de una reglamentación convencional (conflicto de intereses) o, también, la interpretación y correcta aplicación de una reglamentación ya existente (conflicto jurídico).

En aquellos casos en que la negociación se bloquea o no fructifica, teóricamente caben dos procedimientos de solución del conflicto, a través de medidas de presión basadas en huelgas, manifestaciones, encierros u otras medidas de conflicto a disposición de los trabajadores, o a través de lo que se ha dado en llamar medios pacíficos de solución de conflictos, distinguiéndose dentro de éstos, entre los medios judiciales, es decir, el proceso y la sentencia, y extrajudiciales, debiendo diferenciarse entre estos últimos los que se producen sin intervención de terceros, es decir, por la pura actividad negociadora de las partes, de los instrumentados con intervención de terceros, a través de los procedimientos de conciliación, mediación o arbitraje u otras técnicas alternativas de resolución del conflicto'.

En la conciliación la intervención del tercero se limita a procurar el diálogo y el acercamiento entre las partes para que éstas lleguen a un acuerdo y solucionen el conflicto por sus propios medios. La mediación añade un elemento más dinámico, ya que se permite al tercero neutral la elaboración de soluciones y propuestas, que pueden ser alternativas a las planteadas por las partes, y la provisión de información que éstas pueden no haber conocido o desconsiderado; además, en su tipo más formal, el mediador tiene, en el caso de que la negociación fracase y las partes no consigan llegar a un acuerdo, la obligación de elaborar la propuesta de resolución que considere justa o un informe, memoria o investigación imparcial sobre las causas del conflicto y sus posibles soluciones. En el arbitraje interviene un tercero con la función de solucionar el conflicto mediante un laudo o decisión de obligado cumplimiento para las partes en conflicto?

Los medios de solución de conflictos se suelen diferenciar por su origen, entre autónomos y heterónomos, según se creen por los propios sujetos que son partes en las relaciones laborales o por otras instancias, normalmente públicas; por su naturaleza, entre privados y públicos, según su constitución y composición sea privada o estén encuadrados en la Administración; por el sujeto interviniente, se distingue entre medios de autocomposición y de heterocomposición, según se encaucen a través de la negociación entre las partes o a través de la intervención de un tercero neutral o imparcial; por el grado de libertad de las partes en su utilización, se distingue entre medios voluntarios y obligatorios; y, por último, por el carácter de su decisión, entre vinculantes y no vinculantes, según el sujeto interviniente tenga poderes decisorios o de mero acercamiento o propuesta ${ }^{3}$.

En todo caso, conviene tener en cuenta que dichos medios pueden ser, y de hecho son, en la práctica, intercambiables; ya que es muy difícil encontrar una conciliación pasiva en la que el tercero neutral no formule propuestas, es, también, posible que el compromiso planteado por un mediador tenga para las partes un valor dirimente, al igual, que es común la existencia de procedimientos mixtos de mediación-arbitraje en los que sólo se acude al dictado del laudo decisorio cuando han fracasado todos los esfuerzos de composición voluntaria de la controversia, de la misma manera que no es extraño la realización de arbitrajes que tienen para las partes un simple valor consultivo.

Así pues, la negociación colectiva, la huelga y los medios de solución de conflictos forman parte del proceso básico de producción y aplicación de normas en el sistema de relaciones laborales.

Ahora bien, conviene tener en cuenta que el recurso a la huelga en el ámbito público plantea los problemas típicos del conflicto "terciario", problemas que se caracterizan porque la contraposición entre las partes no se produce entre el "patrono" y los "obreros" en el seno de la producción industrial, sino entre el "usuario" o "cliente" y los "empleados" en el seno de una rela- 
ción de servicio, con la correspondiente socialización en negativo del conflicto que no se proyecta sobre bienes inmateriales, es decir, sobre bienes productivos, sino sobre personas, es decir, sobre ciudadanos en uso de su derecho a la prestación de un servicio, con lo que se produce una traslación del conflicto del campo de la Economía al del Derecho.

De aquí que la renuncia a la huelga, su postergación o, incluso, su autorregulación con la introducción de medios pacíficos de solución de conflictos, son modos mediante los que se produce un determinado reconocimiento de que el conflicto en el sector de los servicios debe expresarse de otra forma y con otros medios distintos al conflicto industrial por la especialidad de un campo en el que es posible la producción de un daño a terceros, con los que los mismos huelguistas se reconocen, incluso, en una solidaridad de clase.

En otro terreno, se debe resaltar que los procedimientos extrajudiciales de solución de conflictos, a diferencia de los judiciales, aportan al sistema de relaciones laborales una vía pacifica de solución e integración de las controversias respetuosa con la autonomía de las partes y más satisfactoria en términos de aceptabilidad del resultado, ya que la esencia de estos medios consiste en que los propios sujetos solucionan sus litigios mediante procesos negociales, asistidos, en el caso de la conciliación o la mediación, y delegados, en el caso del arbitraje.

Dados estos antecedentes, no deja de sorprender la poca atención que en el sistema español de relaciones laborales se ha prestado a los medios extrajudiciales de composición de conflictos cuya adecuada regulación y pública promoción se considera por la mejor doctrina laboral como una asignatura pendiente que en el futuro habrá de acometerse, reforma que, desde una perspectiva global, se inscribirá en el marco de la necesaria desjudicialización de la solución de conflictos jurídicos y su complementación o sustitución por soluciones extrajudiciales ${ }^{5}$, y en la búsqueda de un adecuado tratamiento de los llamados conflictos de intereses.

Si esto es así en el ámbito laboral, en el empleo público hay que afirmar la existencia de una significativa pobreza y dispersión en la regulación de los medios de solución de conflictos.

$Y$ ello es especialmente grave si se tiene en cuenta que:

a) Los asuntos de personal siguen ocupando uno de los primeros lugares dentro de los sectores a los que se podrían adscribir las demandas presentadas ante la jurisdicción, provocando efectos distorsionadores en el entero sistema de justicia administrativa ${ }^{6}$.

b) En el ámbito administrativo se carece de un procedimiento especial, sumario y preferente, para el planteamiento y la resolución jurisdiccional de conflictos colectivos ${ }^{7}$.

c) Es difícilmente concebible una intervención judicial contencioso-administrativa sobre un conflicto de intereses, entendi- do éste como aquél que no requiere una solución jurídica sino una solución de compromiso y equidad tendente a salvar un déficit de regulación convencional.

d) En el ámbito administrativo se ha sustituido la conciliación por la reclamación administrativa previa para el personal laboral al servicio de las Administraciones públicas, al tiempo que se ha alterado el sistema de recursos administrativos para los funcionarios públicos, con la consiguiente desaparición de cualquier tipo de recurso administrativo en el ámbito local ${ }^{8}$, por lo que aquellos conflictos individuales que puedan tener relevancia colectiva quedan excluidos, en principio, de todo posible sistema de resolución extrajudicial de conflictos.

De aquí que se haga precisa la búsqueda de soluciones alternativas al proceso administrativo, teniendo en cuenta que no es conveniente establecer un paralelismo excesivo entre los medios alternativos de solución de conflictos y la propia actividad judicial, ya que:

a) La principal función de estos medios estriba en la solución de los conflictos que se producen en un proceso dinámico de negociación colectiva entre las partes, para los que las vías procesales ordinarias no siempre ofrecen las soluciones más idóneas o más satisfactorias en términos formales y sustanciales.

b) No se trata de medios que excluyan el acceso a la jurisdicción sino de sistemas previos y alternativos cuya función es la resolución del conflicto en base a un procedimiento más flexible e informal que fomente un mejor conocimiento de los problemas e intereses en juego, con el menor coste posible en términos de tiempo y recursos, y una mayor factibilidad de la decisión adoptada por ser ésta acordada entre las partes que han de proceder a su implementación.

c) La función de los medios de solución de conflictos no estriba en la resolución de una controversia jurídica sino en la gestión y la resolución de un conflicto que se plantea como un problema en el sistema de relaciones laborales de la correspondiente organización pública.

d) La decisión de acudir a un medio de solución de conflictos alternativo al judicial, supone la asunción por los representantes de la Administración y de los Sindicatos de la propia responsabilidad en la composición de sus diferencias; a partir de aquí, la actitud de las partes y las relaciones que mantengan entre ellas determinará la voluntad de buscar soluciones y la probabilidad de que las encuentren. En otras palabras, la búsqueda y el encuentro de soluciones, dependerá más de los jugadores mismos, que de las normas del juego?.

Una última reflexión parece de interés en el seno de un sistema de negociación descentralizado como es el constituido por el complejo de las entidades locales, la presencia de un órgano institucional que actúe preferentemente como un mecanismo de integración y solución del conflicto es por sí mismo un factor de 
equilibrio y estabilidad del sistema entero, ya que proporciona un asesoramiento implícito sobre cuestiones ciertamente complejas, manteniendo e intensificando la información entre las diferentes unidades de negociación, lo que contribuye en el seno de cada una de las mismas al examen y resolución de los problemas con parámetros comunes equivalentes en términos de comparabilidad y adecuación.

\section{El "Consorci d'Estudis, Mediació i Conciliació a l'Administració Local"}

El "Consorci d'Estudis, Mediació i Conciliació a l'Administració Local", es una Entidad Local, de naturaleza asociativa, integrada por la Diputación de Barcelona, la Federación de Municipios de Cataluña, la Asociación de Municipios de Cataluña, là Federación de Servicios Públicos de la UGT y la Federación Sindical de la Administración Pública de CC.OO.

El Consorcio aparece así como la entidad pública gestora del sistema de solución de conflictos para el ámbito de la función pública local de la provincia de Barcelona, facilitando su naturaleza asociativa la participación de los representantes de las partes que en el futuro habrán de someter sus diferencias a los procedimientos de solución, con lo que se espera poder llevar a cabo eficazmente las tareas propias de la entidad de promover la conciliación y la mediación como medios de apoyo a la negociación colectiva y técnicas alternativas de solución extrajudicial del conflicto.

Entidad pública de gestión promocionada por la Diputación de Barcelona con todo lo que ello implica a nivel presupuestario, de instalaciones y aportación de personal experimentado y, también, de legitimidad, confianza y respeto en relación con los entes locales del ámbito territorial, que día a día se han de relacionar con la institución provincial en el marco de sus competencias de colaboración y cooperación.

Además, en este ámbito, cumple la instalación del Consorcio por parte de la Diputación con el ejercicio de sus funciones de asistencia jurídica y técnica que el ente provincial ha de prestar a los otros entes locales, ofreciendo un servicio de mediación y conciliación, que preventivamente disminuirá la conflictividad jurídica y mejorará la gestión de personal de las diversas corporaciones locales.

En todo caso, conviene tener en cuenta que las finalidades del Consorcio son dobles, ya que se le atribuye la mediación y la conciliación en los conflictos colectivos de intereses y jurídicos que se planteen en el ámbito de actuación de los entes locales de la provincia de Barcelona, pero, también, el estudio, for- mación, investigación y progreso en las relaciones del personal al servicio de la Administración Local.

Estudio e investigación orientados a la obtención de criterios objetivos y experiencias en el ámbito de la resolución de conflictos que permita obtener la información necesaria con la que formular criterios y alternativas para un campo negocial excesivamente centrado en un abanico acotado de cuestiones que por su parquedad y rigidez, a menudo, no permiten concluir adecuadamente un procedimiento de composición del conflicto o el mismo procedimiento de negociación colectiva.

Así, estudios sobre comparabilidad de sectores similares, análisis sobre productividad o retribuciones, investigaciones sobre capacidad de pago de las entidades locales o estudios de las prácticas dominantes, pueden ser el campo principal de actuación; la relación entre la actividad de estudio e investigación, la negociación colectiva y los medios de solución de conflictos ha de ser tan estrecha y, por tanto, la primera tan aplicada, que en los Estatutos del Consorcio corresponde a la propia Junta de Mediación y Conciliación aprobar el plan de actividades de estudio e investigación.

En cuanto a las actividades de formación y fomento de la relación entre las partes, éstas han de permitir incrementar la capacidad del sistema de negociación fomentando la confianza mutua y el conocimiento de las propias posiciones y límites, contribuyendo, también, al conocimiento del marco jurídico en el que se ha de desarrollar el proceso y al manejo de técnicas de comunicación, resolución de problemas y negociación, sobre el convencimiento de que los compromisos eficaces exigen partes eficaces que los articulen y sustenten.

La estructura del Consorcio se diferencia en dos unidades perfectamente delimitadas de conformidad con los propios fines de la entidad. Así, el Centro de Estudios actúa como la unidad administrativa encargada de las actividades de apoyo técnico, es decir, de las actividades de formación, investigación y fomento de las relaciones entre las partes, mientras que la Junta de Mediación y Conciliación es un órgano de composición mixta en él que se reproduce la estructura representativa y paritaria que fundamenta al Consorcio, de este modo, la legitimidad propia del ente asociativo, se traslada a la composición de la Junta de Mediación y Conciliación, y, mediatamente, a los mediadores y conciliadores que ésta designe.

De aquí que la Junta de Mediación y Conciliación, constituida por un Presidente y cuatro vocales, se elija por la Junta de Gobierno del Consorcio, a propuesta, respectivamente, de cada una de las entidades y organizaciones consorciadas, pero con el consenso y la unanimidad de todas.

Una vez constituida, es la propia Junta de Mediación y Conciliación, por mayoría absoluta de sus miembros, aunque hasta ahora se ha utilizado la unanimidad, la que aprueba sus proj"as 
normas de funcionamiento $\mathrm{y}$, por tanto, los procedimientos de apoyo a la negociación colectiva y a la solución extrajudicial de conflictos y, más específicamente, los procedimientos de mediación y conciliación.

\section{La "Junta de Mediació i Conciliació" y sus normas de funcionamiento}

La Junta de Mediación y Conciliación, órgano especializado del Consorcio en las tareas de conciliación y mediación, puede actuar en un ámbito determinado por un doble criterio subjetivo y objetivo.

En el ámbito subjetivo la Junta actuará en todas las entidades locales de la provincia de Barcelona y, también, en sus entes instrumentales, incluidos los de Derecho privado, es decir, en las sociedades mercantiles de capital local o participadas de forma mayoritaria por las corporaciones locales de la provincia de Barcelona.

En el ámbito objetivo, la Junta iniciará sus actuaciones, cuando se trate de los tipos de conflicto siguientes:

a) Conflictos colectivos de intereses o jurídicos, es decir, de interpretación o aplicación de normas.

b) Conflictos plurales de intereses o jurídicos que, por su especial naturaleza o significación, la Junta estime que pueden exceder del interés individual de los afectados.

c) Conflictos individuales, en los que la solicitud de mediación se presente por el órgano unitario de representación de la entidad o por una de las secciones de los sindicatos que integran el Consorcio, siempre que la Junta estime que el conflicto puede tener trascendencia o incidencia en un interés colectivo.

d) Conflictos individuales, en los que la solicitud se presente por un municipio de menos de 500 habitantes con estructura técnica insuficiente para la resolución del conflicto.

Se excluyen del ámbito de los procedimientos de solución de conflictos la materia relativa a la resolución de contratos laborales, las reclamaciones de cantidad y la disciplinaria, tanto laboral como funcionarial.

Como es fácilmente comprensible dicho planteamiento parte de la base de considerar como ámbito natural de actuación el conflicto colectivo de intereses o jurídico, sin embargo, es difícil diferenciar el conflicto individual del conflicto colectivo, ya que a menudo el primero es un síntoma de la existencia del segundo, de aquí las aperturas tendentes a la aceptación de conflictos grupales e individuales con trascendencia colectiva, trascendencia que, además, debe acreditarse por un órgano de representación o una sección de un sujeto colectivo.
Esta posición puede considerarse correcta y merecer un pronunciamiento favorable, pero, la experiencia del Consorcio demuestra la dificultad de objetivar el contenido de un conflicto a la vista de una solicitud de intervención, lo que en la práctica ha conllevado la necesidad de un trámite de calificación del carácter del conflicto, trámite que no se había contemplado en las normas de funcionamiento y que es suplido por la consideración que se otorga por la Presidencia de la Junta a la vista del pronunciamiento de los servicios del Consorcio, pronunciamientos que se intentan objetivar en torno a planteamientos tales como considerar que el incumplimiento de una norma convencional es por sí mismo un conflicto individual con trascendencia colectiva.

La excepción relativa a los conflictos individuales en el ámbito de los pequeños municipios carentes de estructura técnica, hay que ubicarla más en el ámbito de la cooperación que en el de la solución de conflictos, pues a través de este mecanismo se procura que las partes tengan acceso a un asesoramiento jurídico capaz de solventar el conflicto o de indicar las vías de solución correcta en Derecho del mismo.

La solicitud de conciliación o mediación puede ser presentada por las representaciones sindicales y unitarias a iniciativa propia o a instancia de sus representados; igualmente, la solicitud puede ser presentada por las entidades locales o sus entes instrumentales, ya sean de Derecho público o privado.

En todo caso, conviene recordar que la legitimación de las representaciones sindicales se limita a las integrantes del Consorcio en los casos de conflictos individuales, ya que dichas representaciones y las unitarias actúan como garantes de la trascendencia colectiva del conflicto.

Para la tramitación de la solicitud será necesaria la aceptación de la otra parte en litigio, pero dicha aceptación se considerará otorgada cuando el instrumento colectivo aplicable, Convenio o Acuerdo, haya incorporado una cláusula por la que las partes se someten expresamente a los procedimientos de conciliación y mediación previstos para los conflictos que en la interpretación o aplicación de la norma convencional puedan plantearse.

Las tareas de mediación y conciliación se atribuyen expresamente a los miembros de la Junta de Mediación y Conciliación respetándose así la naturaleza de marco de encuentro y representación que todo órgano gestor de los medios de resolución de conflictos debe observar; sin embargo, la Junta, por acuerdo unánime de sus miembros puede elaborar una relación de profesionales y expertos en gestión y administración pública, que pueden ser designados por la misma para participar en los procedimientos de mediación y conciliación; dicha lista de mediadores y conciliadores ha sido ya elaborada integrándola un número de 23 personas, entre las que predominan, fundamentalmente, profesores de Universidad (11), funcionarios con niveles de subdirector y jefe de servicio o sección (5) y profesionales liberales (7). 
La designación de mediador o conciliador para un determinado conflicto y un específico procedimiento, ha de realizarse por la Junta de Mediación y Conciliación, pero, dada la fugacidad de los plazos de actuación y la dificultad de reunir dentro de los mismos a un órgano colegiado, esta facultad ha sido asumida por el Presidente de la Junta, lo que ha de llevar en breve a establecer criterios generales para la asignación de asuntos, que no se han de basar sólo en la rotatividad, sino que deberán tener en cuenta la especialización y la continuidad del tercero interviniente con las partes o las normas ya conocidas por una tarea de conciliación o mediación anterior finalizada con éxito.

Todo ello sin perjuicio de que la designación de mediador 0 conciliador puede hacerse, también, a propuesta de las partes, siempre a partir de una relación de personas seleccionables que les facilite la Junta, que puede confeccionarse, si las partes lo desean, en función de las características que se señalen.

En todo caso, se admite siempre la posibilidad de que el fracaso de un procedimiento de mediación se deba a la actuación del propio mediador, por lo que, comprobado por una de las partes en litigio, o por el propio mediador, que su actuación o sus propuestas no son aceptadas, se podrá de mutuo acuerdo realizar otro intento de resolución del conflicto con otro mediador hasta un máximos de dos.

Los procedimientos de conciliación y mediación se basan en los principios de instancia de parte, celeridad, inmediación, imparcialidad y contradicción, siendo gratuitos para las partes, ya que los mediadores y conciliadores son directamente retribuidos por el Consorcio en base a las aportaciones de la propia Diputación.

Los medios de solución de conflictos se actúan a partir de un escrito introductorio presentado por la parte que desea iniciar el procedimiento, escrito que ha de contener los datos necesarios para la identificación del conflicto, así como la correspondiente manifestación de voluntad o compromiso de someterse a los correspondientes trámites de conciliación y/o mediación, o la indicación del Convenio o Acuerdo donde dicha manifestación se contenga, sin perjuicio de que si en el escrito introductorio sólo existiera constancia de la voluntad de una de las partes, se dé traslado de la solicitud a la otra parte a efectos de obtención de su conformidad, teniendo en cuenta que su negativa sería comunicada a la otra parte y provocaría el archivo de las actuaciones.

También, el escrito introductorio deberá indicar el procedimiento que se desea intentar, es decir, conciliación, mediación o ambos, si con el primero no se obtienen los resultados deseados.

$\mathrm{Al}$ respecto, hay que tener en cuenta que las normas de funcionamiento diferencian el procedimiento de conciliación del de mediación, sin embargo, ésta es una distinción formal, primero, porque ordinariamente las partes optan claramente por el trámite de mediación, lo que presupone automáticamente un esfuerzo de conciliación y, segundo, porque en los pocos casos en que se pretende exclusivamente una conciliación, lo que se acaba produciendo es una mediación de características más informales, cuya diferencia estriba en la inexistencia de aquella propuesta última que a juicio del tercero imparcial podría haber evitado el conflicto.

Recibido el escrito introductorio, confirmada la voluntad de las partes y valorada la solicitud como atendible, el trámite de conciliación ha de realizarse en el plazo máximo de siete días hábiles siguientes al de presentación de la solicitud, mientras que la designación del mediador se ha de producir en el plazo máximo de los cinco días hábiles siguientes y la emisión de su propuesta indicativa en los siete días hábiles siguientes, teniendo en cuenta que sobre la base de la propuesta del mediador convenientemente comunicada a las partes, éstas dispondrán de cinco días hábiles para presentar sus alegaciones, debiendo el mediador realizar su propuesta definitiva en los siguientes siete días hábiles.

La negativa de las partes a aceptar las propuestas presentadas por el mediador tendrá que ser razonada y presentada por escrito, teniendo en cuenta que, de conformidad con el mediador, su propuesta y los motivos de oposición de las partes podrán ser publicados por acuerdo de la Junta de Mediación y Conciliación.

Hasta aquí el trámite de mediación formal, pero, hay que tener en cuenta que el mediador puede convocar a las partes cuantas veces estime pertinente al objeto de reunir el máximo de información y con la posibilidad de provocar concesiones mutuas, con la finalidad última de llegar a un acuerdo sobre la base de las propuestas realizadas, acuerdo que puede contenerse en la correspondiente acta de mediación.

Lo cierto es que los procedimientos de mediación se muestran como procedimientos complejos, fundamentados en una fuerte dosis de experiencia, interacción e intuición; la práctica adquirida hasta el momento nos demuestra que el proceso se desarrolla en tres niveles sucesivos y relacionados; así, en un primer momento, se intenta centrar los puntos objeto de discusión, acotar las demandas y las posibles propuestas de solución, en un segundo momento, se continúa o se desarrolla el proceso de negociación con la asistencia y la colaboración del mediador, normalmente los acuerdos posibles se consiguen en esta etapa, en un tercer momento, se acude ya a la mediación formal, aquí las propuestas del mediador actúan como elemento de presión, y la última como elemento de sanción, sobre la parte que se ha mostrado más irracional o más irreductible en la defensa de sus posiciones, pero lo cierto es que pocos acuerdos se consiguen en esta etapa, aunque, como mínimo, se puede objetivar al máximo el conflicto y reducir la beligerancia de las partes, preparándolas así para una salida judicial al litigio planteado. 
La eficacia de los acuerdos alcanzados entre las partes está en función de la naturaleza jurídica de la relación de empleo y de la tipología del conflicto, estableciéndose las distinciones siguientes:

A) Si el acuerdo afecta a personal sometido a una relación estatutaria y se produce para la resolución de un conflicto colectivo:

a) Vinculará directamente a las partes, si se refiere a materias que se correspondan estrictamente con el ámbito competencial del órgano administrativo que las suscriba.

b) En caso contrario, requerirá para su validez y eficacia la aprobación expresa y formal del órgano del gobierno competente.

B) Si el acuerdo afecta a personal sometido a una relación estatutaria y se produce para la resolución de un conflicto plural o individual, su validez y eficacia requerirá que la entidad local formalice el contenido del acuerdo a través de las correspondientes normas de procedimiento y competencia aplicables a cada caso concreto, en el marco de lo establecido para la terminación convencional del procedimiento en el artículo 88 de la Ley 30/1992.

C) Si el acuerdo afecta a personal sometido a una relación laboral, tendrá la misma eficacia atribuida a los convenios colectivos cuando se produjera en el marco de un conflicto colectivo, o tendrá eficacia obligacional entre las partes firmantes del acuerdo cuando se produjera en el marco de un conflicto plural o individual. En los dos casos, el acuerdo pondrá fin al conflicto, obligará a su cumplimiento y, en los casos de sumisión expresa por convenio colectivo a los procedimientos de conciliación y mediación, lo acordado tendrá las garantías ejecutorias previstas en el artículo 68 de la Ley de Procedimiento Laboral.

\section{La actividad de asistencia de la "Junta de Mediació i Conciliació"}

Fuera ya de los procedimientos estrictos de mediación y conciliación, hay que referirse a la actividad de asistencia jurídica y técnica que desarrolla la Junta de Mediación y Conciliación con respecto a las partes, organizaciones sindicales y ayuntamientos, del sistema de relaciones colectivas del ámbito de la Administración Local.

Dicha función se articula mediante tres técnicas:

a) Actividades de mediación preventiva consistentes en la participación directa de miembros de la Junta o de mediadores de ésta en los procesos de negociación colectiva, a petición expresa de las mesas de negociación o de las comisiones negociadoras.

b) Emisión de informes relativos a la interpretación o aplicación del contenido de los instrumentos de negociación colectiva, siempre que dichos informes se soliciten por las comisiones paritarias de los convenios o las de seguimiento de los acuerdos.

c) Actividades de asesoramiento jurídico y técnico, consistentes en la emisión de informes y dictámenes en materia de solicitudes, recursos y reclamaciones del personal al servicio de las Administraciones Locales del ámbito del consorcio.

Al respecto, es necesario la formalización del correspondiente convenio entre el consorcio y una entidad local por el que se encomienda a la Junta de Mediación y Conciliación el dictamen de todas las propuestas de resolución de recursos y reclamaciones en materia de personal (reclamación-recurso), y el informe de todas las solicitudes que los empleados públicos dirijan a la entidad en la que prestan servicios, especialmente cuando se pretenda la producción de un acto o la revisión de otro anterior (reclamación-solicitud).

El dictamen o informe se ha de emitir con carácter previo a la adopción de la resolución correspondiente sin que tenga carácter vinculante, ya que dicha actividad no ha de suponer para el ente local ninguna disminución de su competencia, siendo el responsable último de dictar las resoluciones con las que finalizarán los procedimientos. Se trata, tan sólo, de que la Junta de Mediación y Conciliación pueda desarrollar ese papel de órgano especializado, profesional y neutral, que permite la resolución de las reclamaciones y recursos en materia de personal, con un mayor grado de garantía y acierto, ya que previamente se ha procedido a separar la gestión ordinaria y su control técnico.

\section{Balance de un breve período}

Si se quisiera hacer un balance de lo que ha sido hasta la fecha la actuación del CEMICAL, podríamos establecer los siguientes datos:

En primer lugar, se ha desarrollado una función informativa que no se había previsto, convirtiéndose el consorcio en un punto de información sobre el sistema de relaciones colectivas en el ámbito de la Administración Local; aquí tres han sido las peticiones características:

a) La elaboración de un documento que sirviera de matriz negocial para las partes en aquellas entidades locales que nunca habían elaborado un acuerdo o convenio, así como el informe de propuestas de acuerdo o convenio sobre cuya legalidad y posible marco de contractualidad se duda. 
b) La información sobre el posible desarrollo del proceso electoral en el marco del nuevo modelo de designación de los miembros de los comités de empresa y juntas de personal de conformidad con la reforma legislativa desarrollada en el año anterior.

c) La posible validez de formas distintas de articulación interna o compleja de los órganos unitarios de representación de los funcionarios públicos, concretamente reglamentos internos de las juntas de personal y posibilidad de constitución de un órgano de representación unitaria de carácter supramunicipal.

En segundo lugar, hay que decir que el organismo ha sido utilizado como un instrumento de presión sindical en la dinámica de negociación entre las partes, fundamentalmente en materias de conflictos individuales con trascendencia colectiva. Así, la mera apertura del procedimiento y la comunicación a la parte local para su aceptación de la composición ha provocado un principio de acuerdo sin necesidad de que el procedimiento se haya desarrollado por completo.

En tercer lugar, el instrumento ha demostrado su mayor virtualidad en el ámbito del conflicto colectivo de intereses y en el de la interpretación de las normas colectivas, elaborándose acuerdos completos en su seno y con la intervención de mediadores del mismo, a la vez que los propios instrumentos de negociación colectiva han comenzado a recoger cláusulas de remisión al acto de mediación dirimente de este organismo para la resolución de los conflictos de interpretación y aplicación que sobre los mismos pudieran suscitarse.

Por último, hay que decir, que si quisiéramos elaborar una pequeña radiografía del tipo de solicitudes de conciliación y mediación que se están produciendo y tramitando en el seno del CEMICAL, podríamos establecer los siguientes datos:

a) En cuanto a la frecuencia hay que decir que tras un periodo inicial de arranque de seis meses, el número de solicitudes de intervención parece haberse estabilizado en las 3/4 mensuales.

b) Dichas solicitudes se han presentado mayoritariamente por los sindicatos representados en el Consorcio, aunque últimamente se detecta un mayor número de solicitudes procedentes de órganos unitarios del personal.

c) Las solicitudes se presentan en el ámbito de las relaciones de personal de municipios capitales de comarca o municipios metropolitanos.

d) En un primer momento las solicitudes se presentaron como individuales con trascendencia colectiva, hoy la norma ordinaria es que el conflicto sea un conflicto colectivo de intereses o de interpretación y aplicación de la norma colectiva.

e) Los temas más tratados han girado en torno a la interpretación y cumplimiento de cláusulas contractuales en materia de asignación de complementos retributivos, clasificación y provisión de puestos de trabajo y cómputo de jornadas y horarios. f) El colectivo que mayor conflictividad está generando es el de policía local.

g) La mitad de los conflictos planteados han sido aceptados por la otra parte; en la totalidad de los conflictos tramitados con la conformidad de las dos partes, hasta el momento se ha obtenido un acuerdo admitido por las mismas.

h) Conviene prestar una especial atención a las cuestiones de legitimación, con la finalidad de que los acuerdos obtenidos sean fácilmente trasladables al ámbito negocial de referencia, en especial es fundamental que al proceso de conciliación o mediación sean convocadas todas las organizaciones sindicales legitimadas para negociar en función de su representatividad.

\section{El arbitraje}

Hay que decir con toda claridad que el CEMICAL no es un órgano gestor de procedimientos arbitrales; es más, esta posibilidad considerada en su momento, fue rechazada por los entes y organizaciones integrantes del consorcio, por entender que los medios de solución de conflictos han de expresar la voluntad conjunta de las partes a través de un proceso negocial desarrollado por las mismas con participación de un tercero neutral que ha de orientar y procurar la transacción.

La idea de fondo es que los procedimientos de solución de conflictos deben ser una continuación de la negociación y su resultado ha de ser considerado como equivalente a un acuerdo $y$, en cambio, no deben ser concebidos como el principio de una actividad jurisdiccional cuyo equivalente fuera un laudo sustitutorio de la actividad de las partes.

Con todo hay que subrayar que el arbitraje puede ser extraordinariamente útil si se concibe como una delegación acotada de las partes al árbitro para la elaboración de un acuerdo que ellas mismas hubieran podido negociar o decidir ${ }^{10}$. Aquí se produciría un compromiso previo de sometimiento que puede contener una serie de directrices y límites que las partes pueden establecer a la actividad y la decisión del árbitro, de tal manera que la tarea del mismo se acota de forma que no sustituya a la iniciativa negociadora de las partes y permita solventar aquellos problemas concretos que entorpecen o retrasan el proceso de negociación y la suscripción de un acuerdo; evidentemente, el grado de vinculación de las partes y el laudo que se dictará tendría que respetar los trámites sucesivos de aprobación que se establecen para la actividad negocial de la Administración, salvando siempre la competencia de los respectivos órganos de gobierno.

A la admisión de esta hipótesis tendría que ayudarnos la concepción del arbitraje como un supuesto de negociación delegada y su consideración como una tarea material, ya que la eficacia de la cosa decidida no es un dato intrínseco al arbitraje, sino 
que debe ser incorporado como un plus por el ordenamiento jurídico. Así, el laudo arbitral formaría parte del proceso de negociación y consistiría en una delegación en favor de un tercero de la facultad de dotar de contenido a un tema concreto y acotado por la voluntad de las partes; la no adecuación de la actividad del árbitro a la voluntad manifestada en el compromiso arbitral o su extralimitación en la delegación otorgada sería causa de invalidez de la decisión, ya que las atribuciones del árbitro, en este caso, traen causa y dependen de la voluntad de las partes.

A partir de aquí, parece posible la aceptación del arbitraje voluntario en materia de función pública en aquellos supuestos en los que previamente se hubiera admitido la posibilidad de negociar ${ }^{11}$, ya que, en definitiva, el arbitraje no sería más que la delegación de esta posibilidad en favor de un tercero, en el marco de una cuestión previamente definida por el compromiso arbitral, cuya área de incertidumbre se limita a su contenido, en un ejemplo típico de lo que es un negocio jurídico per relatio$n^{12}$.

En todo caso, hay que tener presente que el régimen jurídico del laudo arbitral será el que en cada caso particular rija para el negocio principal objeto de arbitraje, de forma tal que para su validez y eficacia habrá de ser aprobado por el órgano de gobierno o aceptado por el órgano administrativo competente, siguiendo las reglas de procedimiento y competencia establecidas ${ }^{13}$.
- Profesor de Derecho Administrativo de la Universidad de Barcelona. Jefe de Estudios de la Diplomatura en Gestión y Administración Pública de la misma Universidad. Presidente de la Junta de Mediación y Conciliación del CEMICAL. Ex-Coordinador del Area de Régimen Interior, Planificación y Hacienda de la Diputación de Barcelona.

1 Aunque los medios de solución extrajudicial de conflictos más conocidos entre nosotros son los de mediación, conciliación y arbitraje, en la experiencia comparada existen una serie de variaciones sobre estos tipos, como son los "buenos oficios", la "determinación de los hechos" o los "minijuicios"; véase al respecto DELGADO PIQUERAS, F., "La "administrative dispute resolution Act" de los Estados Unidos: Introducción, traducción y notas", RAP, n 131 (1993).

2 Véase al respecto SALA FRANCO,T; ALBIOL MONTESINOS, I., Derecho Sindical, Tirant lo Blanc, Valencia, 1992, p.527-529.

3 Tomamos esta clasificación de GONZÁLEZ DEL REY RODRíGUEZ, Ignacio, "Los acuerdos autonómicos sobre procedimientos voluntarios de solución de conflictos laborales", RTSS, octubre-diciembre 1993, p.84; clasificaciones similares son corrientes en la doctrina laboral, por ejemplo, la de CASAS BAAMONDE, Mํㅡㄹ Emilia, "La solución extrajudicial de los conflictos laborales", RL II-1992, p.29.

4 Sobre la "terciarización" del conflicto industrial, véase ACCORNERO, Aris, "Conflitto, "Terziario" e Terzi", Giomale di diritto e di relazioni industriali, 25 (1985).

5 Para el campo administrativo, véase el trabajo de DELGADO PIQUERAS, Francisco, "Las nuevas conquistas del principio constitucional de participación, terminación convencional del procedimiento y medios consensuales de solución de conflictos administrativos", RJCM 18 (1994).

6 Es suficientemente significativo al respecto el trabajo de MARTÍN MATEO Ramón, Eficacia social de la Jurisdicción Contencioso-Administrativa, INAP, Alicante, 1989. Sobre la situación de crisis del modelo actual del proceso contencioso, TORNOS MAS, Joaquín, "La situación actual del proceso contencioso- administrativo", RAP 122 (1990), p.110; con expresa mención de los problemas de congestión motivados por los recursos sobre función pública.

7 Véase al respecto, MARTÍNEZ ABASCAL, Vicente-Antonio, "El planteamiento jurisdiccional de los conflictos colectivos en la función pública", $R L$ II-1988, p. 435 y ss.

${ }^{8}$ Tal como se refleja en el título del trabajo de ROMERO HERNÁNDEZ, Federico, "Alternativas de los recursos administrativos en la Administración Local", RAAP 19 (1994), p.11 y ss.

9 Véase el estimulante estudio de KOLB, Deborah M., Los mediadores, MTSS, Madrid, 1989.

${ }^{10}$ Véase al respecto, BALLESTER PASTOR, María Amparo, El arbitraje laboral, MTSS, Madrid, 1993, p.80.

${ }^{11}$ Existe un alto grado de acuerdo sobre esta posibilidad en la doctrina italiana, véase al respecto CAIA, Giuseppe, Arbitrati e modelli arbitrali nel diritto ammnisitrativo. I presupposti e le tendenze, Giuffrè Editore, Milano, 1989; CECCHELLA, Claudio, L'arbitrato nelle controversie di lavoro, Franco Angelli, Milano, 1990.

${ }^{12} \mathrm{El}$ negocio jurídico per relationem se fundamenta en que existe un negocio previo, basado en el compromiso arbitral, el contenido del cual ha de ser determinable, a través del correspondiente laudo, mediante remisión a elementos extraños al negocio, es decir, mediante el árbitro; la tesis en BALLESTER PASTOR, María Amparo, El arbitraje laboral, MTSS, Madrid, 1993, p.152 y ss.

${ }^{13}$ Lo que evidentemente supone la facultad de la Administración de aceptar 0 no el laudo, teniendo en cuenta que ésta será la primera interesada en hacer un uso moderado de dicha facultad, para no desprestigiar el procedimiento ante la otra parte, tal como por otra parte sucede en la experiencia comparada, véase al respecto DELGADO PIQUERAS, Francisco, "La *administrative dispute resolution Act. de los Estados Unidos: Introducción, traducción y notas", RAP no 131 (1993), p.567 y ss. 